\title{
Using Eight Agile Practices in an Online Course to Improve Student Learning and Team Project Quality
}

\author{
Andrea R. Hulshult \\ Miami University \\ Timothy C. Krehbiel \\ Miami University
}

As online learning continues to increase, instructors need different teaching methods and technologies for teaching online. This study explores how Agile practices are integrated into an online IT course. We focus on incorporating eight Agile practices (team charters, daily stand-ups, Kanban boards, story cards, MoSCoW, timeboxing, showcases, and retrospectives). Students were surveyed at the end of the course and the results indicate Agile enhanced students' learning and increased the quality of their final project.

\section{INTRODUCTION}

One promising approach to enhance collaboration and group projects in online courses is Agile methodology. According to Krehbiel et al., (2017), Agile is a collection of practices aimed at enhancing group collaboration. Agile began in the computer software industry in the early 2000s to manage software development projects. When working in an Agile environment, teams focus on collectively articulating their goals, reflecting on their work and making necessary adjustments, having authentic group interactions, improving team dynamics, and encouraging innovation (Smith \& Sidky, 2009). Agile teams work in iterative, usually two-week, work cycles that have a regular cadence of feedback and reflection practices. Teams get real-time feedback on their work, reflect on their functioning as a team by discussing what is going well and what needs improved, make adjustments to their work, and repeat. Agile teams have higher quality outcomes and better meet their customers' needs compared to traditional project management models (Krehbiel et al., 2017).

As Agile continues to integrate into other industry sectors, including education, researchers are adapting the traditional Agile values for their industry's specific value system. Chun (2004) introduced the Agile Teaching/Learning Methodology (ATLM) in several computer science courses at the City University of Hong Kong. ATLM is a teaching methodology that leverages concepts from Agile that encourage adaptability to help students learn:

"By agility, we mean the ability for the teacher to quickly adapt and change course pace and possibly structure to suit the needs and abilities of the students. The main objective for teaching is to help students learn." (Chun, 2004, p.12) 
Although only applied to Computer Science courses, Chun believed that the methodology was general enough to be used in other disciplines. A survey of current scholarship finds that instructors across a variety of disciplines have looked to improve their pedagogy through implementing Agile practices. Since Agile is rooted in the software development industry, a majority of scholarship discusses implementing Agile in computer science, but scholarship exists for other disciplines (Linden, 2018; Mahnič \& Časar, 2016; Anderson \& Romney, 2014; Guercio \& Sharif, 2012; Dey, et al., 2009; Romney, 2009). McBride (2005) proposed using the values of Extreme Programming (a common method used by software developers) to teach an e-commerce course. D'Souza and Rodrigues (2015) report on Agile teaching methods in engineering, while Piunno et al. (2014) discuss their use in an interdisciplinary senior capstone course for students majoring in the physical or biological sciences. These papers express the view that Agile teaching encourages student questions and working collaboratively. They also report better experiences for the instructor and/or student when using Agile teaching. The parallels between Agile software development and active and cooperative learning have also been noted (Magana, Seah \& Thomas, 2018; Stewart et al., 2009).

Pope-Ruark (2012) has successfully used Agile practices in her English classes in complex group projects to encourage trust, engagement and accountability among students. Krehbiel et al. (2017) provide examples of Agile methods being used in a variety of disciplines including computer science, software engineering, information systems management, supply chain management, technical writing, early childhood education, civic studies, and political science. A survey of students enrolled in these courses indicated students believed that Agile contributed to a more effective learning experience and more efficient use of their time and credited Agile methods in enhancing teamwork on group projects and the quality of class project deliverables (Krehbiel et al., 2017, p. 104).

While all the previously mentioned research discusses Agile enhancing learning, it is important to note that none of the papers mentioned address using Agile in online courses. There is an interest in applying concepts in the classroom to improve the educational experience (Parsons \& MacCallum, 2019); however, there is little research on using Agile in online courses. According to Noguera, GuerreroRoldán, and Masó (2018), collaborative learning is highly demanding and becomes more challenging when conducted in an online environment. Students feel frustrated when performing online collaboration due to difficulty communicating and an imbalance of team member participation (Capdeferro \& Romero, 2012). Online instructors and students need various strategies to improve online collaboration and online group projects. The adaptive and people-focused nature of Agile allows it to be used as a tool for online instructors in all disciplines to enhance collaboration and improve the work produced by group projects.

This paper is organized as follows. First, for the context and background, we provide an overview of online learning and teaching practices. Second, we discuss the history of Agile and summarize different Agile education manifestos. Third, we describe and discuss the results of our study. We implemented eight Agile practices in an online course and discuss the students' survey results of using these Agile practices in a collaborative online environment and multiple group projects. In the online course where this study was conducted, students meet asynchronously online and never meet face-to-face.

\section{ONLINE LEARNING OVERVIEW}

According to the 2018 report Grade Increase: Tracking Distance Education in the United States, distance education enrollments have increased for the fourteenth year in a row. During the Fall 2016 academic term, 6,359,121 students were taking at least one distance learning course, comprising 31.6\% of all higher education enrollments (Seaman, Allen \& Seaman, 2018). The steady growth of online enrollments has institutions focused on the technologies to deliver online learning in order to help students collaborate. Advances in online learning platforms have brought new methods to integrate demonstrations, assessments, lecture recordings, video conferencing, and virtual interactions to support student learning and collaboration (Lindgren \& McDaniel, 2012). While technology has brought software advances to enhance the delivery of online learning, improvements in helping students to collaborate in an online environment are still needed (Noguera et al., 2018). 
A major concern for online courses is the level of interaction needed to facilitate collaboration and meaningful, shared discourse in an online environment. Online courses have lower retention rates than traditional face-to-face courses, which can be a barrier to the continued growth of online learning (Allen \& Seaman, 2013). In a study conducted by Tseng, Wang, Ku, and Sun (2009), they discovered students' satisfaction with collaboration in online courses depends on their trust with their classmates and their institution's organizational practices surrounding online learning.

\section{Online Teaching Best Practices}

Sun and Chen (2016) reviewed 47 studies on online teaching and learning since 2008 to discover effective online teaching and learning practices. The framework for their study is based on Garrison, Anderson, and Archer's (2009) theory that social presence, cognitive presence, and teaching presence must be present for successful online education. Social presence is most simply defined as student participation in the online course (Sun \& Chen, 2016). John Dewey supports the concept of social interaction as part of the learning process. He says an individual cannot perform his own activities or work without taking the activities of others into account (Dewey, 1966).

Cognitive presence is how students perceive their learning satisfaction (Sun \& Chen, 2016). Initial, continuous, and consistent interaction between student and instructor is a basic principle of online teaching (Dykman \& Davis, 2005). Students should have the ability to talk with other students, post their work, and receive feedback from the instructor in an informal (message board or discussion room) and formal (grade feedback) manner. Informal communication opportunities allow for open and honest conversations in chat rooms or online messaging. Formal communication opportunities allow students and faculty to discuss course content and assignments.

Teaching presence includes the instructional design elements of the course, discourse facilitation, and instruction (Sun \& Chen, 2016). Activities involved in teaching presence in online courses are creating online presentations, lecture notes, media-based mini lectures, individual and group assignments, deadlines for assignments, and support for using the online learning management system.

Sun and Chen's study (2016) also defined eight pedagogical practices for effective online teaching: building relationships, engaging with students, timeliness, communication, organization, technology, flexibility, and high expectations. The study suggests that online instructors should build positive rapport with students by having empathy, being passionate about teaching, and wanting students to succeed. Furthermore, online students want instructors to respond in a timely manner to messages about the course, and they also want assignments graded timely. Engaging with students is possible in an online platform by participating in discussion boards, assigning meaningful group work, and encouraging students to share their backgrounds and work experiences.

Effective and successful online curriculum and instruction requires a different approach to interaction among students and the instructor (Crawford-Ferre \& Wiest, 2012). Online students need elements that appeal to different learning styles and learning experiences, just as in traditional face-to-face classes. These elements often include the technology and functionality built into a learning management system such as video, group chat, messaging, virtual web conferences, downloadable files, email, and webcams. A combination of the these mentioned elements provide different methods to interact based on a student's preference.

Initial, continuous, and consistent interaction between student and instructor is a basic principle of online teaching (Sun \& Chen, 2016; Dykman \& Davis, 2005). This social aspect needs to carry over into online learning in the form of interaction-students must interact with one another and the instructor to create meaning and knowledge through shared discourse. Tee and Karney (2010) suggest that this communication include a blend of formal and informal opportunities. Students should have the ability to talk with other students, post their work, and receive feedback from the instructor in an informal (message board or discussion room) and formal (grade feedback) manner. Informal communication opportunities allow for open and honest conversations in chat rooms or online messaging. Formal communication opportunities allow students and faculty to discuss course content and assignments. 
In traditional face-to-face classrooms, student and instructor interaction naturally occurs with conversation and discussion. In an online environment, the instructor needs to foster, encourage, and support interaction. Fish and Wickersham (2009) stress that online instructors need to communicate differently and have techniques that help enhance relationships with their students, and that effective interaction in an online learning environment contributes to positive student performance, grades, and course satisfaction.

\section{AGILE}

Agile software development was developed in 2001 to bring adaptability and change in the software development industry (Beck et al., 2001). Historically, software development teams develop software in a "waterfall" method where the requirements, design, and functionality planning are decided upfront, which does not allow for reflection and adaption as needs change. Beck et al. (2001) introduced Agile to the masses with the Manifesto for Software Development. The core values of the original manifesto are individuals and interactions over processes and tools, working software over comprehensive documentation, customer collaboration over contract negotiation, and responding to change over following a plan. Agile is an umbrella term for a different way of thinking and working that covers an assortment of practices and methodologies. While there are different Agile approaches, such as Scrum, many use similar concepts such as iterative work cycles, daily stand-ups, story cards, timeboxing, planning and estimating, showcases, and retrospectives. These Agile concepts require teams to communicate and collaborate, and most Agile methodologies have a built-in time to reflect on how the team is working together so they can improve their communication skills. Since Agile focuses on iterative work cycles with frequent communication and collaboration between the customer and team, communication evolves with each iteration as the team learns to work together and adapt to the client's changing needs. Other industry sectors, including education, are beginning to examine how Agile can improve outcomes for their teams.

Agile has been successful in managing software development projects and teams (Dewi \& Muniandy, 2014), and now other industry sectors, including education, are beginning to examine Agile practices. In education, several researchers have developed educational manifestos that mirror the original Agile Manifesto, but have aligned the Agile values with educational contexts. In this paper we briefly overview the main Agile educational manifestos that currently exist. In 2011, Peha responded to low teacher morale and slowing growth in student achievement in K-12 schools by seeking to help school principals become more effective leaders by writing the Agile Schools Manifesto. Specifically, Peha's Agile Schools Manifesto called for the prioritization of individuals and interactions over processes and tools, meaningful learning over the measurement of things, stakeholder collaboration over complex negotiation, and responding to change over following a plan.

Kamat (2012) called for changes in three core areas of educational work: teaching/learning, evaluation, and administration and wrote the Agile Manifesto in Higher Education that emphasized teachers and students over administration and infrastructure, competence and collaboration over compliance and competition, employability and marketability over syllabus and marks, and attitude and learning skills over aptitude and degree.

Royle and Nikolic (2016) proposed an Agile Pedagogy Manifesto calling for teachers to prioritize the development of students' skills, learning, and understanding rather than detailed lesson plans. They proposed a collaborative approach focusing on reflective planning and review. Krehbiel et al. (2017) wrote their Agile Manifesto for Teaching and Learning which is a statement of core professional and personal values, and a guide for the day-to-day work of educators.

In addition to educational manifestos, research is surfacing about using Agile for group projects in face-to-face classrooms (Krehbiel et al., 2017; Pope-Ruark et al., 2011; Rico \& Sayani, 2009). One recent study was conducted by Woods and Hulshult in 2018. These researchers conducted a study using Agile practices for a group project in a face-to-face classroom. Students in this study indicated that using Agile practices helped them to work collaboratively together to develop quality projects that were an 
improvement over their previous non-Agile based projects. Their results also reported that $81 \%$ of students will continue to use some of the Agile practices they learned. It is natural to ask if Agile practices can be transferred to online courses to improve group collaboration and project quality.

Agile methodology focuses on individuals, collaboration, and reflecting and responding to change in intervals. Krehbiel et al. (2017, November) suggest 12 tools and rituals often used in Agile can be used in the classroom. In this paper, we show how online instructors can adapt eight of these practices: Team charters, daily stand-ups, Kanban boards, story cards, MoSCoW, timeboxing, showcases, and retrospectives. The four practices discussed by Krehbiel et al. (2017, November) not integrated in this study are fist to five, horseraces, silent brainstorming and affinity grouping, lean coffee.

\section{Team Charters}

Team charters, sometimes referred to as social contracts in Agile environments, create transparency, positively impact student accountability and can help "troubled" teams negotiate difficult issues. A social contract is the set of rules a team agrees to that are above and beyond what their basic project roles and responsibilities mandate (Agile Academy, 2018). Questions that teams must discuss can include: Who are we? What is our team name? What are our values? How will we handle conflict? How will we run our meetings? How will we manage our work? How will we know if we are successful? How will we have fun? Among the benefits of a social contract are that (1) teams need to own their practices and standards to have commitment to them; (2) it contributes to a safe working environment giving people the power to have conversations about behaviors considered inappropriate; and (3), it helps build the unique character of the team and creates a shared sense of identity (Agile Academy, 2018).

In an online classroom, team charters can be discussed in a team discussion space or in a collaborated document. The team can refer to the discussion or document as they progress in their project if behaviors arise that are addressed in the team charter.

\section{Daily Stand-Ups}

The daily stand-up is a core practice in Agile methodology and is used to provide transparency and the ability to adapt, if needed (Schwaber \& Sutherland, 2017; Sutherland, 2014; LeanDog, 2012; Smith \& Sidky, 2009). Daily stand-ups are a daily 15-minute meeting where the team meets to discuss what they finished yesterday, what they are working on today, and what is preventing them from doing their work. An online instructor can post the following daily stand-up questions, modeled after the industry Agile daily stand-up questions, in the chat room or on a discussion board at any frequency (daily, weekly, or biweekly): (a) What did you accomplish this week? (b) What do you plan to work on between now and next week? and (c) What are the obstacles, questions, or impediments that are preventing you from making progress?

As the students post their answers to these daily stand-up questions, it becomes transparent to the instructor (and the students) what students are working on and if obstacles exist. Based on this interaction, the instructor can post helpful suggestions or offer additional resources. The instructor cannot see how the students are progressing or what questions they have without this interaction point. Daily stand-ups can help online instructors cultivate interactions and build respect and rapport in their virtual classrooms. Danielson (2013) indicates that both words and actions set the tone for a classroom. If there is a common theme among the daily stand-up responses, the instructor can respond, which helps the students gain trust and respect that the instructor is engaged and actively participating in their learning. The responses to the daily stand-up allow the instructor to immediately make adaptations (if necessary) to help keep the class on schedule and focused on the learning outcomes. Students see the instructor answering their questions, providing clarifying information, and adapting the course to their needs, which helps build positive interaction and rapport.

If an instructor notices that a particular student is struggling based on the daily stand-up questions, the instructor can contact the student and investigate the issue. This allows the instructor to hopefully connect with the student, answer any questions, and steer the student in the right direction before it becomes a bigger issue. Agile daily stand-ups are also useful in a fast-paced course, complex unit, or a sprint course 
because they provide immediate feedback to the instructor to see if the students' learning is where it needs to be and if they are keeping up with the material. Instructors can then provide timely, clarifying information if necessary.

\section{Kanban Boards}

Kanban boards are tools that help individuals or teams visualize work and workflow, as well as optimize the way work gets done (LeanDog, 2012). The name comes from the Japanese word Kanban, meaning "visual signal" or "card," and references the process improvement approach known as the Kanban Method (Lean Kit, 2018). Kanban boards are visual planning and organization tools to create transparency and can produce better results in less time. A physical Kanban board could be a whiteboard that contains headings such as backlog, in progress, and done with post-it notes (called story cards) that represent different requirements or tasks. A virtual Kanban board could be a Trello board (www.trello.com), which is an online whiteboard where headings and post-it notes can also be added and organized. The post-it notes or story cards on a Kanban board represent a requirement or task that needs completed. Story cards help break the work of a large assignment down into smaller pieces so a team can visually see all the work and complete it a little at a time.

In online courses, Kanban boards are a tool individual students or student groups, such as teams, can use to monitor, organize, and track work. Managing group work in an online course can be challenging, since students do not often reach out for help until the deadline is very near. Using a virtual Kanban board helps students and instructors. A team of students in an online course can setup a virtual Kanban board and create story cards for all the requirements they must complete for an assignment. These story cards can be assigned out to different team members, which helps create accountability within a team. Instructors can request that students add them to the Kanban boards so they can track each team's progress and intervene when necessary.

There are several ways to integrate Kanban boards into online courses. One activity is to have the students or teams post a screen print of their virtual Kanban board into the discussion space and answer the daily stand-up questions (see previous section). This type of discussion activity helps students and instructors see the progress of each team, ask questions, get help with obstacles, and for the instructor to provide feedback to help the team stay on track (or get back on track). A second activity is to have the students record a screencast or video explaining their virtual Kanban board, the story cards they are working on, their progress, and how their team is working. This activity also helps students learn a new software to make the screencast or video. Instructors can receive insight as to how the teams are progressing on a project and provide any necessary feedback or support.

\section{Story Cards}

Story cards are an Agile practice teams use to represent requirements for a product or project, and they are displayed, physically or virtually, on a Kanban board. A story card contains a sentence or two that describes a necessary function or requirement for a project (LeanDog, 2012). A good practice is to have one requirement per story card. For example, students working in teams on a group project review the project rubric or requirements and make story cards for each requirement. Students may also add story cards for an editorial review, printing, or report cover design. Each story card represents a requirement that needs completed. Story cards contain criteria that must be met for the card to be marked "complete," and they are testable - a team can test if the work produced as a result of a story card is working and complete. Story cards are placed on Kanban boards to track the progress of class projects to help student teams track a project's requirements, so they have a visual picture of what needs done. Team members can assign story cards to themselves and report to their teammates during stand-ups what progress they have made on that story card. Story cards allow instructors to see the progression of work and can provide support if needed.

In online courses students and instructors use electronic Kanban applications, such as Trello, to create virtual story cards and to manage their progress. In virtual Kanban software, different columns can be setup for story cards that need completed, story cards in progress, and ones completed. This allows 
students to see what work needs completed and helps them be accountable for the story cards. The story cards can be moved from column to column to help track progress. A virtual Kanban board with story cards helps students to evenly distribute the work by assigning the story cards among team members. This prevents one student from doing the majority of the work. Students can log into Kanban boards via a website or mobile application and can invite other students and the instructor to join the board. Story cards are helpful in an online course because they allow students and the instructor to track the work on an assignment without meeting face-to-face. Students can log into the virtual website they are using for their Kanban board and see the status of the project. In an online course, daily stand-up questions can be posted in the discussion area of the learning management system, so students can see the status of each group member's work.

\section{MoSCoW}

MoSCoW is a prioritization tool often used where a deadline is fixed so that the focus must be on the most important requirements. The MoSCoW tool originates from Scrum, a type of Agile. All requirements are put into one of four categories: Must have (M), Should have (S), Could have (C) and Won't have (W) (Krehbiel et al. (2017, November). The deadline is often defined via timeboxing (see below). The MoSCoW prioritization method is a helpful tool for both students and instructors in online courses to prioritize work. Student teams who use a virtual Kanban board can mark each story card with an " $M$ " if the requirement is a "Must," a " $S$ " if the requirement is a "Should," a " $C$ " if the requirement is a "Could," and a "W" if the requirement is a "Won't." This helps students to prioritize their work and complete the work marked with a " $\mathrm{M}$ " first, so they are focused on creating the most important requirements first.

The MoSCoW method can help instructors pre-prioritize assignments and requirements for students. For example, instructors can mark assignments or requirements of assignments with the MoSCoW method to help students know what to do first, since communication in an online course can be limited. Instructors can use the MoSCoW method to prioritize the learning for a course. For example, an instructor can mark each assignment in the course with the MoSCoW method to help prioritize the assignments and readings for the course.

In online courses, the MoSCoW method is helpful for students working in teams to prioritize work that needs accomplished on a project. MoSCoW works best if students have an online Kanban board with story cards. After a student team creates their story cards for the work they need to do on an assignment, they can mark each story card with an M, S, C, or W. This helps the team to see what tasks must be completed, should be completed, could be completed, or won't be completed. Students should start working on the must cards first, then the second, and so on. If students use the MoSCoW method with their story cards, the online instructor can review the Kanban boards and see if a team is on track and has the right focus for the assignment.

\section{Timeboxing}

In an Agile environment, a timebox is a set duration of time an iteration or activity lasts (Stellman \& Greene, 2014; Sutherland, 2014). The timebox for an Agile iteration in a typical software development project is usually two weeks, so the development team has two weeks to complete the user stories they are assigned. In non-software projects, a timebox can be any set duration of time to complete some activity. In education, a timebox can represent a month, a semester, a module, or how many minutes the instructor wants to spend on a class activity. (For in-class activities, it is helpful to set a timer to help the class work within the boundaries of the timebox, thus limiting unnecessary conversations and helping students focus on task at hand.)

For online instructors timeboxing can help students organize their time. Instructors can state how much time an assignment should take. This helps students plan accordingly, but it also helps them to know if something is taking too long. This can be an indicator that they need clarification on the assignment or need to refocus their efforts. Online student teams can set a timebox for how long they will work on each story card to help them stay focused. 


\section{Showcases}

A showcase or "show and tell" is an Agile practice where an Agile team demonstrates the work they completed during the latest iteration (round of work) to their customer or stakeholder (LeanDog, 2012). This allows an Agile team or group to receive feedback on their work, which they can incorporate into the next iteration. Showcases help support the Agile Manifesto value of customer collaboration over contract negotiation.

In the classroom, a team (or individual student) can demonstrate the work they have completed on a project or assignment to gain feedback from the instructor, peers, or an actual customer if the course has a client project. This allows another opportunity to get feedback, make any corrections or adjustments, and plan for the remaining work. Showcases also help students to be accountable for their work and to their team since they have to show their progress--who wants to demonstrate a poorly created product? While conducting a showcase is easy in a face-to-face course, it can also be done in an online course. Students can create a screencast or recording of the work they have done so far. For classes that are asynchronous and have no synchronous components, each team member can present their piece of the project or one team member can slice all the individual videos together. An instructor can request that students post the videos in an online discussion so students can watch and comment on each other's videos. If the learning management system supports groups, the instructor can create review groups, and assign groups to review the videos.

\section{Retrospectives}

Agile teams use retrospectives to discuss what went well, what went wrong, and what they could do to improve (Sutherland, 2014; Schwaber \& Sutherland, 2013; Smith \& Sidky, 2009). Retrospectives are insightful and reflective. In industry, retrospectives are meetings that occur after end of a two-week work cycle where the team meets to discuss what went well, what went wrong, and what could they improve for the next work cycle. The team then applies this information to their next work cycle.

Instructors need to see what elements in their lessons impact student learning, what should be maintained, and what revisions should be made for the future (Danielson, 2013). Retrospectives allow online instructors to reflect on their course material and make any needed adjustments for the present or future. In online courses, receiving feedback about the course as the course progresses helps the instructor to understand how the course is going since no verbal feedback is given as in a face-to-face class.

There are multiple options for implementing retrospectives in an online course. The retrospective occurs at the end of a module. unit, assignment, or course. Instructors can post the standard retrospective questions in the discussion space in the online course: a) What went well during this module? (b) What went wrong during this module? and (c) What could we do differently to improve this module or the next one? We suggest giving students a deadline to respond and requiring them to respond to at least two other students' posts. The answers to the retrospectives give instructors an insight to the module, unit, assignment, or course, and allows them to clarify any concerns, collect feedback for improvement, and make any changes that can positively influence student learning and outcomes for the remainder of the course. There is no need to wait for the end-of-term assessments to see what students' perspectives were on the course. An online instructor can use the responses to critically analyze and reflect on the module/assignment/lesson from a student's perspective. The answers to retrospective questions allow an instructor to identify knowledge gaps and provide clarifying follow-up before the next learning module begins. The instructor also gains insight into which learning activities were successful and which activities need edited for future use.

Retrospectives also increase course interaction because students learn from each other as they read the questions and answers, and as they read the instructor's responses. Retrospectives provide a mechanism for the instructor to increase interaction with the students. 


\section{IMPLEMENTING THE EIGHT AGILE PRACTICES}

The eight Agile practices discussed above were implemented in a semester-long systems design and lifecycle course delivered $100 \%$ online. This sophomore level course is required for undergraduate students majoring in Computer Information Technology. The course includes a semester-long group project where teams of 4 to 5 students are required to develop a solution to a hypothetical scenario and then use project management practices to manage the development of their solution. This was the first time Agile practices were used in this course.

\section{Survey Results}

At the end of the course, all 21 students were asked to answer a voluntary survey concerning the use of Agile practices in the course. All 13 questions in the survey used a standard five-point Likert scale with a " 1 " signifying strong disagreement with a given statement and a " 5 " signifying strong agreement. The first five questions asked questions about how Agile influenced their learning, use of time, team work, project quality, and overall Agile experience. The next eight questions focused on the students' experience using each of the eight Agile practices.

Altogether 16 students participated in answering the first five questions. Table 1 displays the survey's results for the questions pertaining to students' perceptions of using Agile in an online course to enhance or improve overall course outcomes. As the data indicate, students found great value in using Agile in an online course. Students agreed that using Agile in an online course "lead to a more effective learning experience," "lead to a more efficient use" of their time and helped them to create project "deliverables of higher quality." The survey results also indicate that students believed using Agile on their group projects was a "beneficial experience."

Twelve students answered the next set of eight questions regarding Agile practices. The data reported in Table 2 show similarly high levels of student satisfaction with using particular Agile practices in an online course as they did with using Agile overall. The Agile practice that received the highest ranking was MoSCoW. Using the MoSCoW method to prioritize story cards and tasks helped the students and their teams to determine what tasks needed to be completed first.

The Agile practices that received the lowest rankings were daily stand-ups and showcases. The authors are not surprised by the low rankings, since these two Agile practices are difficult in an asynchronous online environment. Agile daily stand-ups require that teams meet daily or on a regular basis to discuss what they did since they last met, what they are working on now, and what obstacles they have. In an asynchronous online course, it is challenging to get students to meet virtually as a team. The daily stand-ups in this course where conducted in the discussion area of the LMS or each team decided to conduct their stand-ups in an alternative format such as text messaging or another social media tool. It is interesting to note that in a previous study, daily stand-ups were ranked high in a face-to-face course (Krehbiel et al., 2017).

Agile showcases are also more challenging to use in an online course. An Agile showcase is a demonstration of a team's progress or product so they can receive feedback from their stakeholder. This is challenging in an asynchronous course because the class never meets all at the same time. In this course, the students made a video showcase of their team's project, which were posted online in the LMS, and other students and the instructor gave feedback. Many groups did not meet to make the video; each team member recorded their piece of the video and one group member sliced it all together. It should be noted that the variability in responses in Table 2 was the highest and that 5 of the 11 respondents rated showcases a "5." 
TABLE 1

STUDENT PERCEPTION OF USING AGILE IN AN ONLINE COURSE

\begin{tabular}{|ll|l|}
\hline Question & $\begin{array}{l}\text { Overall } \\
\text { n=16 }\end{array}$ \\
\hline $\begin{array}{l}\text { Using Agile on the projects lead to a more } \\
\text { effective learning experience than if Agile had } \\
\text { not been used. }\end{array}$ & $\begin{array}{l}\text { Mean } \\
\text { Std. Dev. }\end{array}$ & $\begin{array}{l}4.38 \\
0.62\end{array}$ \\
\hline $\begin{array}{l}\text { Using Agile to complete the projects lead to a } \\
\text { more efficient use of our time. }\end{array}$ & $\begin{array}{l}\text { Mean } \\
\text { Std. Dev. }\end{array}$ & $\begin{array}{l}4.31 \\
0.62\end{array}$ \\
\hline $\begin{array}{l}\text { Using Agile to complete the projects made us } \\
\text { work better together as a team. }\end{array}$ & $\begin{array}{l}\text { Mean } \\
\text { Std. Dev. }\end{array}$ & 4.06 \\
& 0.77 \\
\hline $\begin{array}{l}\text { Using Agile to complete the projects made the } \\
\text { deliverables of higher quality. }\end{array}$ & $\begin{array}{l}\text { Mean } \\
\text { Std. Dev. }\end{array}$ & 4.25 \\
\hline $\begin{array}{l}\text { Overall, using Agile on the projects was a } \\
\text { beneficial experience. }\end{array}$ & $\begin{array}{l}\text { Mean } \\
\text { Std. Dev. }\end{array}$ & 4.19 \\
\hline
\end{tabular}

TABLE 2

STUDENT PERCEPTION OF USING AGILE PRACTICES IN AN ONLINE COURSE

\begin{tabular}{|c|c|c|}
\hline Question & & $\begin{array}{l}\text { Overall } \\
\mathbf{n}=12\end{array}$ \\
\hline $\begin{array}{l}\text { Using team charters improved my overall } \\
\text { online learning experience. }\end{array}$ & $\begin{array}{l}\text { Mean } \\
\text { Std. Dev. }\end{array}$ & $\begin{array}{l}4.00 \\
1.04\end{array}$ \\
\hline $\begin{array}{l}\text { Using daily stand-ups improved my overall } \\
\text { online learning experience. }\end{array}$ & $\begin{array}{l}\text { Mean } \\
\text { Std. Dev. }\end{array}$ & $\begin{array}{l}3.82 \\
1.08\end{array}$ \\
\hline $\begin{array}{l}\text { Using a Kanban or Trello board improved my } \\
\text { overall online learning experience. }\end{array}$ & $\begin{array}{l}\text { Mean } \\
\text { Std. Dev. }\end{array}$ & $\begin{array}{l}4.00 \\
0.77\end{array}$ \\
\hline $\begin{array}{l}\text { Using story cards improved my overall online } \\
\text { learning experience. }\end{array}$ & $\begin{array}{l}\text { Mean } \\
\text { Std. Dev. }\end{array}$ & $\begin{array}{l}3.91 \\
1.04\end{array}$ \\
\hline $\begin{array}{l}\text { Using MoSCoW improved my overall online } \\
\text { learning experience. }\end{array}$ & $\begin{array}{l}\text { Mean } \\
\text { Std. Dev. }\end{array}$ & $\begin{array}{l}4.27 \\
0.90\end{array}$ \\
\hline $\begin{array}{l}\text { Using timeboxing (set time periods to get the } \\
\text { work done) improved my overall online } \\
\text { learning experience. }\end{array}$ & $\begin{array}{l}\text { Mean } \\
\text { Std. Dev. }\end{array}$ & $\begin{array}{l}4.18 \\
0.87\end{array}$ \\
\hline $\begin{array}{l}\text { Using showcases improved my overall online } \\
\text { learning experience. }\end{array}$ & $\begin{array}{l}\text { Mean } \\
\text { Std. Dev. }\end{array}$ & $\begin{array}{l}3.91 \\
1.22\end{array}$ \\
\hline $\begin{array}{l}\text { Using retrospectives improved my overall } \\
\text { online learning experience. }\end{array}$ & $\begin{array}{l}\text { Mean } \\
\text { Std. Dev. }\end{array}$ & $\begin{array}{l}4.18 \\
.075\end{array}$ \\
\hline
\end{tabular}




\section{Qualitative Feedback}

Students also contributed written feedback about using Agile in this online course. All the responses indicate that Agile was a positive aspect of the online course. Two pieces of feedback indicate that the online group work was a valuable learning experience. Here are some representative responses:

- Continue teaching about Agile!

- We should keep doing more lessons on Agile, as I feel it is one of the most important aspects of the course and something everyone could benefit from in the future.

- Please, I beg you to do this next semester, show the applications of concepts like Agile through the course.

- The group work in this course was executed in such a way that it was enjoyable to do. Often group work in online courses is nothing but a burden, but the way this course did it made it easy.

\section{CONCLUSION}

As online learning continues to be a pillar in academic institutions' long-term strategy, we must examine alternative methods for teaching online and improving online courses for students. The results of the authors' research indicate that using Agile in an online course "lead to a more effective learning experience," "lead to a more efficient use" of their time, and helped them to create project "deliverables of higher quality." The survey results also indicate that students believed using Agile on their group projects was a "beneficial experience." Written feedback from several students indicates that Agile enhanced their online group work experience. Agile should continue to be researched as a teaching and learning practice for online courses.

The authors' advice for implementing Agile in online courses (and face-to-face) is to start small and only implement a few Agile practices at a time. Agile is an iterative process, so if an Agile practice you try does not work, try a different one for the next iteration (e.g., the next unit). Based on the authors' experiences, Agile practices work differently in different courses, so do not be afraid to try a variety of practices. If there is a practice that does not seem to work well, conduct an Agile retrospective. Ask the class what went well with the practice, what did not go well, and what could make it better. This feedback will help to make any adjustments for the next unit or course.

\section{REFERENCES}

Agile Academy (2018). Social contract. Retrieved from Agile Academy's Knowledge hub http://www.agileacademy.com.au/agile/knowledgehub/agile-practice

Allen, E. I., \& Seaman, J. (2013). Changing course: Ten years of tracking online education in the United States. Report of the Babson Survey Research Group. Retrieved from http://onlinelearningconsortium.org/survey_report/changing-course-ten-years-trackingonline-education-united-states/

Anderson, R. C., \& Romney, G. W. (2014). Student experiential learning of cyber security through virtualization. Journal of Research in Innovative Teaching, 7(1), 72-84.

Beck, K., Thomas, D., et al. (2001). Manifesto for agile software development. Retrieved from www.agilemanifesto.org/

Capdeferro, N., \& Romero, M. (2012). Are online learners frustrated with collaborative learning experiences? International Review of Research in Open and Distance Learning, 13(2), 26-44.

Chun, A. H. W. (2004). The agile teaching/learning methodology and its e-learning platform. In Lecture Notes in Computer Science - Advances in Web-Based Learning, 3143, 11-18. Springer-Varlag Heidelberg.

Crawford-Ferre, H. G., \& Wiest, L. (2012). Effective online instruction in higher education. Quarterly Review of Distance Education, 13(1), 11-14. 
D’Souza, M. J., \& Rodrigues, P. (2015). Extreme pedagogy: An agile teaching-learning methodology for engineering education. Indian Journal of Science and Technology, 8(9), 828-833.

Danielson, C. (2013). The framework for teaching evaluation instrument, 2013 edition. Charlette Danielson.

Dewey, J. (1966). Democracy and education: An introduction to the philosophy of education. New York: The Free Press.

Dewi, D., \& Muniandy, M. (2014). The agility of agile methodology for teaching and learning activities. Software Engineering Conference (MySEC), 2014 8th Malaysian, 255-259.

Dey, P. P., Cruz, A. P., et al. (2009). Agile problem driven teaching in science and technology. Proceedings of the 2009 American Society for Engineering Education Pacific Southwest Conference, San Diego, CA, March 19-20, 2009, 197-212.

Dykman, C., \& Davis, C. (2005). Online education forum: Part two - teaching online versus conventionally. Journal of Information Systems Education, 19(2), 157-165.

Fish, W. W., \& Wickersham, L. E. (2009). best practices for online instructors: Reminders. Quarterly Review of Distance Education, 10(3), 279-284.

Garrison, D. R., Anderson, T., \& Archer, W. (2009). Critical thinking, cognitive presence, and computer conferencing in distance education. American Journal of Distance Education, 15(1), 7-23.

Guercio, A., \& Sharif, B. (2012). Being agile in computer science classrooms. AURCO Journal, 17(1), 41-62.

Kamat, V. (2012). Agile manifesto in higher education. Proceedings 2012 IEEE Fourth International Conference on Technology for Education, 231-232.

Krehbiel, T. C., Cosmah, M. L., Hulshult, A. R., \& Kleiman, I. L. (2017, November). Increasing student engagement and performance by incorporating agile tools and rituals. Paper presented at the annual meeting of the Decision Sciences Institute, Washington, D.C.

Krehbiel, T. C., Salzarulo, P. A., Cosmah, M. L., Forren, J., Gannod, G., Havelka, D., Hulshult, A. R., \& Merhout, J. (2017). Agile Manifesto for Teaching and Learning. The Journal of Effective Teaching, 17, (2), 90-111.

Lean Kit (2018). What is an online kanban board? Retrieved from https://leankit.com/learn/kanban/online-kanban-board/

LeanDog (2012). Agile discussion guide, version 3.1. LeanDog, Inc.: Cleveland, OH.

Linden, T. (2018). Scrum-based learning environment: Fostering self-regulated learning. Journal of Information Systems Education, 29, (2), 65-74.

Lindgren, R., \& McDaniel, R. (2012.). Transforming online learning through narrative and student agency. Educational Technology \& Society, 15, (4), 344-355.

Magana, A. J., Seah, Y. Y. \& Thomas, P. (2018). Fostering cooperative learning with scrum in a semicapstone systems analysis and design course. Journal of Information Systems Education, 29(2), 75-91.

Mahnič, V., \& Časar, A. (2016). A computerized support tool for conducting a scrum-based software engineering capstone course. International Journal Of Engineering Education, 32(1A), 278-293.

McBride, N. K. (2005). A student-driven approach to teaching e-commerce. Journal of Information Systems Education, 16, (1), 75-83.

Noguera, I., Guerrero-Roldán, A.-E., \& Masó, R. (2018). Collaborative agile learning in online environments: Strategies for improving team regulation and project management. Computers \& Education, 116, 110-129.

Parsons, D., \& MacCallum, K. (Eds.) (2019). Agile and lean concepts for teaching and learning: Bringing methodologies from industry into the classroom. Singapore, Springer.

Peha, S. (2011). Agile schools: How technology saves education (Just not the way we thought it would). Info $Q$. Retrieved from http://www.infoq.com/articles/agile-schools-education.

Piunno, P. E., Boyd, C., Barzda, V., Gradinaru, C. C., Krull, U. J., Stefanovic, S., \& Stewart, B. (2014). The advanced interdisciplinary research laboratory: A student team approach to the fourth-year research thesis project experience. Journal of Chemical Education, 91(5), 655-661. 
Pope-Ruark, R. (2012). We scrum every day: Using scrum project management framework for group projects. College Teaching, 60(4), 164-169.

Pope-Ruark, R., Eichel, M., Talbott, S., \& Thornton, K. (2011). Let's scrum: How scrum methodology encourages students to view themselves as collaborators. Teaching and Learning Together in Higher Education. Retrieved from http://teachingandlearningtogether.blogs.brynmawr.edu/archivedissues/may-issue/lets-scrum.

Rico, D. F., \& Sayani, H. H. (2009, August). Use of agile methods in software engineering education. In Proceedings Agile Conference, 2009. AGILE'09. (pp. 174-179). IEEE.

Romney, G.W. (2009). The integration of ruby on rails as an agile teaching tool in IT curricula. Proceedings of the 2009 American Society for Engineering Education Pacific Southwest Conference. San Diego, CA, March 19-20, 2009, 481-492.

Royle, K., \& Nikolic, J. A. (2016). A modern mixture, agency, capability, technology and 'scrum': Agile work practices for learning and teaching in schools. Journal of Education \& Social Policy, 3(3), 37-47.

Schwaber, K., \& Sutherland, J. (2017, November). The scrum guide. Scrum.org. Retrieved from: https://www.scrum.org/resources/scrum-guide

Seaman, J., Allen, I., \& Seaman, J. (2018). Grade increase: Tracking distance Education in the United States. (Report of the Babson Survey Research Group). Retrieved $\mathrm{http}$ ://onlinelearningconsortium.org/survey_report/changing-course-ten-years-tracking-onlineeducation-united-states/

Smith, G., \& Sidky, A. (2009). Becoming agile in an imperfect world. Manning Publications Co.: Greenwich, CT.

Stellman, A., \& Greene, J. (2014). Learning agile. Sebastopol, CA: O’Reilly Media, 2015.

Stewart, J. C., DeCusatis, C. S., Kidder, K., Massi, J. R., \& Kirk, A. M. (2009). Evaluating agile principles in active and cooperative learning. Pace University. Retrieved from csis.pace.edu/ ctappert/srd2009/b3.pdf

Sun, A., \& Chen, X. (2016). Online education and its effective practice: A research review. Journal of Information Technology Education: Research, 15, 157-190.

Sutherland, J. (2014). SCRUM: The art of doing twice the work in half the time. Crown Business: New York.

Tee, M., \& Karney, D. (2010). Sharing and cultivating tacit knowledge in an online learning environment. International Journal of Computer-Supported Collaborative Learning, 5(4), 385-413.

Tseng, H., Wang, C., Ku, H., \& Sun, L. (2009). Key factors in on-line collaboration and their relationship to teamwork satisfaction. The Quarterly Review of Distance Education, 10(2), 195e206.

Woods, D., \& Hulshult, A. (2018). Using agile practices to scaffold team projects in an IT ethics course. Journal of Computing Sciences in Colleges, 34(1), 17-23. 